\title{
5 Identity through Change and Substitutivity Salva Veritate
}

\author{
Reinaldo Elugardo and Robert J. Stainton
}

\section{Introduction}

This chapter has three modest aims: to present a puzzle, to show why some obvious solutions aren't really "easy outs," and to introduce our own solution.

The puzzle is this. When it was small and had waterlogged streets, Toronto carried the moniker 'Muddy York'. Later, the streets were drained, it grew, and Muddy York officially changed its name to 'Toronto'. Given this, each premise in the following argument seems true. Yet the conclusion is a contraction.

(P1) $\quad$ Muddy York = Toronto

(P2) Muddy York evolved into Toronto.

(P3) The context '__ evolved into Toronto' is transparent, that is, it allows substitution of coreferring singular terms.

(P4) It's not the case that Toronto evolved into Toronto.

(C1) Toronto evolved into Toronto (by P1, P2, and P3).

(C2) Toronto both did and did not evolve into Toronto (by P4 and C1).

Of course the puzzle isn't about Toronto. It's not even about cities: the same conundrum arises with names of people (think of the well-known case of 'Cassius Clay' and 'Mohammed Ali'), diseases ('coronovirus' and 'SARS'), and so on. Nor is the puzzle just about "evolving into": it can be generated with 'changed into', 'turned into', 'became', and so forth. Generalizing, an instance of the puzzle can be got whenever we have both accidental change-that is, qualitative change that preserves numerical identity—together with a change in name. 
Before moving forward, two caveats are in order. We approach the puzzle as philosophers of language, not as metaphysicians; and our proposed solution to it is linguistic. No doubt the puzzle, being about change, time, identity, and the like, also raises metaphysical questions galore; but we take our linguistic points to be compatible with any remotely plausible metaphysical account of these. ${ }^{1}$ Related to this, we do not put forward our solution as definitive. We think it's superior to the "easy outs" that we reject, but it's not without its problems. In particular, it does leave us with one nonobvious metaphysical commitment.

\section{Four "Easy Outs"}

We now consider four natural reactions to the puzzle. ${ }^{2}$ Each corresponds to the rejection of a premise in the argument above. All four "outs" are initially attractive. We will try to show, however, that in each case, the supposed "easy out" either requires biting a hard philosophical bullet or suffers from obvious empirical faults.

Start with (P1) and (P2), since they can be dealt with quickly. Giving up (P1) avoids the substitution of 'Toronto' for 'Muddy York' at (C1). But to deny that Muddy York is, that is, is numerically identical to, Toronto, apparently involves giving up the identity over time of the one city. That's a very significant cost, to say the least. It means, for example, that the city's residents didn't truly celebrate Toronto's bicentennial in 1993, since no one thing has lasted that long. One might say: Cities are such fluid social creations that this isn't such a cost after all. But remember: the puzzle generalizes. We mentioned people (and diseases). Thus, rejecting (P1) means, for instance, that one can't really punish the very person who did the crime, after a name change, but only some other person who stands in the right causal-historical relation to the renamed evil-doer. We could equally have given examples of land-masses, species, etc. And so on. It seems, then, that for any changing object that has different labels at different times, we'd have to abandon identity. Of course some philosophers might be tempted to give up genuine identity over time. But this just is bullet-biting, and we think that can be avoided. Giving up (P2) doesn't look any more promising. It seems a matter of historical fact: Muddy York evolved into Toronto. (You can look it up, if you don't believe us.) You might object that given (P4) and (P1), we simply have to reject (P2). But again, that's another bullet: this move lets metaphysical scruples trump seemingly obvious empirical observations. We hope to show that all such moves can be avoided. 
Abandoning (P3) seems a far more attractive option. In fact, when we first noticed the puzzle we thought we had found a new kind of opacity, similar to 'The temperature is rising; the temperature is 92 degrees; so, 92 degrees is rising'. Careful reflection convinced us, however, that '__ evolved into Toronto' behaves differently from familiar opaque contexts. First, in familiar opaque contexts one can substitute genuinely nondenoting definite descriptions and get truths. For instance, because 'is looking for' is opaque, it can be true that an (unfortunate) mathematician has devoted his life to looking for the largest prime. But only genuine denoting terms can give rise to true substitution instances of '__ evolved into Toronto' and the like, so that context doesn't behave like genuinely opaque contexts do. It may be objected to this test that we do say things like 'Saint Nicholas evolved into Santa Claus'. But when this is true, the expressions do have some kind of denotation, so they aren't really genuinely denotationless. (To see this, note that when we are using 'Saint Nicholas' in this way, it's also true that he has a beard, is over twenty years old, etc.) It's expressions of the genuinely nondenoting kind, like 'the largest prime', that distinguish genuinely opaque contexts from others-and they do not give rise to true instances of '__ evolved into _ '. Second empirical difference: It seems that evolving into (etc.) is something the object considered in itself does: it's not a guise, or a linguistic description, which determines whether the thing evolved into such-and-such or didn't. And being de re in that way is another hallmark of referentially transparent contexts. Third, appeal to opacity is insufficiently general. Similar sorts of things happen where there is no triggering verb at all. Consider, in this regard, a much older and more familiar puzzle: 'That cute baby is that old geezer. That old geezer has a beard. Therefore, that cute baby has a beard'. The problem here surely is not that '_ has a beard' disallows substitutivity salva veritate. So, if we can find a solution that covers this old case and also solves our puzzle, that would be preferable. Finally, opacity should not be introduced without necessity. Whatever mechanism one endorses to explain away nonsubstitutivity-reference shift, parataxis, and so on-that mechanism should be deployed sparingly. And, as will emerge below, there's no need to posit opacity here. So much, then, for solving the puzzle by rejecting (P3). That's not really such an "easy out" either, because it is empirically inadequate.

The final "easy out" is to reject (P4). To give up P4, one can follow Jennifer Saul, and suggest that although it is very odd to say that Toronto evolved into Toronto, it's not actually false. The comparison here, drawn from Saul (1997), is with (1) and (2): 
(1) Superman went into the phone booth and Clark Kent came out.

(2) Superman went into the phone booth and Superman came out.

She suggests that if (1) is true, (2) is true as well. (How could it not be, since '_ came out of the phone booth' is patently transparent?) Still, despite this, we hear the two sentences as having different truth-values because of pragmatics. Ditto, one might say, for 'Toronto evolved into Toronto' versus 'Muddy York evolved into Toronto'. The key difference with our puzzle, however, is that whereas sentence (2) can be true, and would even strike us as true (e.g., if the famous gentleman went in with his cape on, and came out the same way), '__ evolved into _ ' is irreflexive. No object can evolve into itself, and under no circumstances does it strike us as true that one does so. ${ }^{3}$ (Though see below for some complications.) So giving up (P4) doesn't seem consistent with an important fact about the semantics of ' evolved into _.'.

To sum up so far, we have presented our puzzle, namely that premises (P1) through (P4) seem true, though they jointly yield a contradiction; and we have canvassed four "easy outs," each corresponding to the rejection of a premise, suggesting that rejecting the premise in question either requires biting a philosophical bullet, or is empirically inadequate. The final step, which we turn to shortly, is to present our own proposal. First, however, we need to introduce and defend an idea that will play a crucial role.

\section{Polysemy}

We maintain that names of places, people, and things are polysemous in a way that can solve our puzzle. We will defend this idea in two stages. First, we explain what polysemy in general is. Then, we introduce the particular way in which, according to us, names like 'Toronto' are polysemous.

Polysemy is a kind of ambiguity, but one that is less problematic than homophony, as in 'bank [of a river]' and 'bank [where I have my checking account]'. Polysemy understood broadly is a matter of numerous related senses-with theorists differing on what it is to have different "senses." However implemented, polysemy is systematic enough that it doesn't postulate hard-to-acquire unrelated meanings. (See Apresjan 1974, Moravcsik 1998, and Pustejovsky 1998 for detailed discussion.)

Here are a series of examples. Sometimes a product name refers to the model, but in other uses it refers to a token thereof. Thus consider (3).

(3) Rob's Ford is reliable. 
One can use this sentence to say, about the kind of Ford Rob owns, namely the Focus, that it's reliable. Such a statement would be false: the Focus is notoriously unreliable. But consider a context in which Rob owns two cars, a peculiarly unreliable Honda and a Focus that, against all odds, is very reliable. Then, even if the kind of Ford Rob owns is notoriously unreliable, one can still speak truly with (3). This sort of example supports the idea that the phrase 'Rob's Ford' is polysemous, being used here to refer to a type and there to refer to a token. Notice that this doesn't require two independent lexical entries for 'Ford', since the phenomenon occurs with kinds quite broadly. For example, think of (4):

(4) Every Canadian coin has a monarch's face on it.

This is true of every denomination, but false of some of the more wellworn metallic tokens. Nor is type-token the only place where "multiplicity of related senses" shows up. Consider these examples, adapted from Pustejovsky 1998 and Nunberg 1979, 1995.

(5) 'Denny's is located on the corner of 5th and Broadway' versus 'Denny's once had controversial hiring practices'.

(6) 'Mary broke the bottle' versus 'The baby finished the bottle'.

(7) 'The window is rotting' versus 'Mary crawled through the window'.

(8) 'The Toronto Star fired its editor' versus 'John spilled coffee on the Toronto Star'.

(9) 'Saul Bellow died recently' versus 'Saul Bellow would make a terrific dissertation topic'.

(10) 'Washington is a great tourist destination' versus 'Washington declared war'.

In (5), the shift is something like token-type: from a particular location to the corporation as a whole. In (6), 'the bottle' shifts from standing for the container, to standing for its contents, and in (7), 'the window' similarly shifts from the outside to the inside. In (8) and (9) one refers first to the producer, then to (something like) the product. Finally, in (10), 'Washington' is used first to refer to the city as a location, then to refer to it as seat of government. (Compare also: 'Washington beat the Maple Leafs to win the Stanley Cup'.)

Again, in contrast with the homophonous 'bank' (river versus financial institution), one doesn't have to memorize two autonomous meanings for the specific terms 'bottle', 'window', and 'the Toronto Star', and so on. What 
the language learner needs to internalize is that there is a comparatively systematic effect of multiple senses that applies generally to models, containers, figures, and products (among other cases). That is polysemy.

Before laying out in more detail our polysemy idea for names, it may help to foreshadow how appeal to polysemy would solve the puzzle. Recall the 'Rob's Ford' example, and consider the following argument, which parallels the one we began with:

$\left(\mathrm{P} 1^{*}\right)$ The car in the driveway = Rob's Ford.

$\left(\mathrm{P}^{*}\right)$ The car in the driveway is unreliable.

(P3*) The context '_ is unreliable' is transparent, that is, it allows substitution of coreferring singular terms.

$\left(\mathrm{P} 4^{*}\right)$ It's not the case that Rob's Ford is unreliable.

$\left(\mathrm{C}^{*}\right)$ Rob's Ford is unreliable (by P1, P2, and P3).

$\left(\mathrm{C} 2{ }^{\star}\right)$ Rob's Ford both is and is not unreliable (by P4 and C1).

$\left(\mathrm{P}^{*}\right)$ is an identity at a time; surely it can't be denied. (P2*) is an empirical fact: the 2000 Ford Focus, which is the one that Rob owns, is an extremely unreliable car. It has, for instance, been subject to a record number of recalls. As for $\left(\mathrm{P3}^{*}\right)$, if '__ is unreliable' is opaque, then just about anything is. As for $\left(\mathrm{P}^{*}\right)$, it's an empirical fact too: Rob's Ford is even more reliable than his Honda, and Hondas are one of the most reliable cars on the road. We thus have four premises that seem true, and a conclusion that is a contradiction. Should we bite the bullet, and reject one of the premises? Clearly not. In this case, it's quite obvious what is wrong with the argument: on the sense of 'Rob's Ford' on which $\left(\mathrm{P} 1^{\star}\right)\left(\right.$ and $\left.\mathrm{P} 4^{*}\right)$ is true, namely the token sense, $\left(\mathrm{P} 2^{\star}\right)$ is false; and on the sense of 'Rob's Ford' on which (P2*) is true, namely the model sense, $\left(\mathrm{P}^{*}\right)$ (and $\left.\mathrm{P} 4^{*}\right)$ is false. The trouble with the argument, then, is that its premises seem true because of equivocation on the polysemous phrase 'Rob's Ford'.

So much for introducing polysemy as a general phenomenon. That it exists at all is at least somewhat controversial (e.g., Fodor and Lepore [1998] take issue with it), but we think something in the neighborhood is real and ubiquitous, and we'll assume as much in what follows. Taking polysemy in general as a given, our idea with respect to the puzzling argument with which we began is that polysemy of an unnoticed sort occurs with names of places, people, and the like. In particular, and putting things crudely for the time being, such names have two lexically specified usepotentials: they have the linguistic function both of being used to refer to 
an object over time, and to refer to that object at a time. ${ }^{4}$ Using 'Toronto' as an example, the idea is that the meaning of this name permits two literal uses: to refer to the city as a whole, across its entire history, and to refer to the city at a particular stage of its growth and development.

Two clarifications. First, the idea is not merely that 'Toronto' can be used to refer to various things. Of course that's true, because speakers can in general refer with a word $w$ to lots of things that $w$ does not designate. Nor, second, is the idea that there is a "meaning" of 'Toronto' for each thing it can be used literally to refer to. Since there are ever so many stages at which Toronto exists, there are every so many ways of referring to Toronto at a time: on July 22, 2005; in 1929; on VE Day; and so on-and it's clear that 'Toronto' does not have, as a matter of its linguistic job, a distinct use-potential for each of these. Rather, the idea, again crudely for now, is that 'Toronto' has two relevant senses: one for referring to the object over time, and the other for referring to that object during the contextually salient period of time.

Why think that names for people, places, things, and the like are polysemous in this at-a-time versus over-time way? Let's start with three points in favor. First, notice that 'John Graves Simcoe, having died in 1806, lived in Muddy York, not in Toronto' sounds true. More exactly, we think it can be used literally to make a true statement. But it couldn't do so if 'Muddy York' and 'Toronto' could only be used literally to refer to the entire object-over-time. Also, 'Muddy York is now overrun with SUVs and cookiecutter houses' sounds true. Or better, we think it too can be used literally to make a true statement. But it couldn't be so used if 'Muddy York' could only be deployed literally to refer to the long-ago object-at-a-time. Thus polysemy for such expressions seems to be required on independent grounds: object-at-a-time for the former usage, object over time for the latter. Second, the effect is quite general. It's not just names that are here used literally to talk about objects-at-a-time and are there used literally to refer to objects-over-time. Nominals in general can be used literally with each kind of satisfier. Thus, to take an example from Ted Sider (personal correspondence), 'Some frontier towns evolved into major centers of culture' can easily be used literally to say something true, unlike 'Some major centers of culture evolved into major centers of culture'. Or, to take an example from Lenny Clapp (personal correspondence), one could point at a picture and then at a crusty oldster and say, using a demonstrative rather than a name, 'That cute baby evolved into that grizzly old codger'. That statement could be true. But 'That grizzly old codger evolved into that grizzly old codger'? So, introducing polysemy for this kind of name is not ad 
hoc. Third, and speaking of generality, introducing polysemy for referring terms allows us to explain away other apparent examples of opacity. Consider: 'Lunch is a tuna fish sandwich; lunch is always served at noon; therefore, a tuna fish sandwich is always served at noon'. The premises are true. The conclusion is false. Still, it's not plausible that '_ is always served at noon' is opaque. But how then is substitution failure to be explained? The obvious answer is that 'lunch' is polysemous, being used here for a daily eating activity, there for the item to be eaten on a specific day. Roleoccupier cases like this turn out to be quite common. (Here's another case. 'The boss is getting younger; Samantha is the boss; therefore, Samantha is getting younger'.) Noting this, consider again the familiar example 'The temperature is rising'. Our initial thought, following Montague, was that '_ evolved into _' exemplified a variety of opacity along these lines. We were wrong about the opacity of '__ evolved into _.'. But maybe we were right about the similarity. Perhaps what's going on in this more familiar example is not that '_ is rising' is resistant to substitution of coreferring terms-with the "functional sense" being contributed instead of the usual referent-but rather that 'The temperature' is polysemous: here it is used to refer to the role, there it is used to talk about the present occupier (e.g., 22 degrees). In other words, coreferring terms can be substituted in this context; the thing is, 'The temperature' when used to pick out the role, doesn't actually corefer with '22 degrees'.

Consider now four objections to our polysemy hypothesis for 'Toronto' et al., and our replies. First, introducing multiple senses will strike some as a violation of "Grice's razor": do not posit ambiguities without necessity. One obvious reply is that there is necessity here, because there are usages that cannot be adequately described without varying senses. Though we think this reply carries some weight, we recognize that such a response will seem question-begging in the present context. Another reply, then, which skirts the necessity issue, is this. Polysemy can be understood in at least two ways. On the first, polysemous terms are assigned a series of contents, and context selects among these. So understood, polysemy really is full-blown ambiguity, so, for better or worse, this version does introduce extra type meanings. Happily, there's another way of spelling out the idea. On the second version, the polysemous term is assigned a single content that can permit literal reference to something more determinate on the basis of the context. To give an example, on the first account 'Ford' would mean both FORD MODEL and FORD INSTANCE; then a use of 'Rob's Ford' would exhibit one of these two preset senses. On the second account, 'Ford' would simply mean FORD; but that content would not sin- 
gle out tokens or types as what could be literally referred to, allowing a speaker to refer literally to either. The phrase would thus have both usepotentials determined by its one standing meaning-not because it had two meanings. The cost of the second approach, if it is a cost, is that the sentence type 'Rob's Ford is unreliable' would not express a contextindependent proposition. Indeed, it's consonant with this approach that sentence types in general do not have propositions as their meaning. Rather, as per Strawson (1950), their meaning allows them to be used by agents to state various propositions. The benefit is that this one sentence could be used literally to assert (at least) two quite different kinds of propositions, thereby accounting for the observed usage. For reasons of theoretical economy, and for other reasons that are quite independent of the puzzle, we happen to favor the latter option. And it isn't open to the objection under consideration, whether or not additional senses are required to describe the data correctly.

Here is a second objection, due to Mark Moyer (personal correspondence). Consider sentence (11).

(11) Muddy York evolved into Toronto, and its bicentennial was in 1993.

On our view, 'its' would have to refer to the object-over-time, since that is the thing that survived for 200 years, but the only antecedents available each would be used to refer to the object-at-a-time, since it is those that "evolve into." Thus, our view seemingly predicts that (11) will be semantically anomalous. But, continues the objection, the sentence is perfectly fine. Hence, there must be something wrong with our analysis. Our reply is that polysemous terms in general just do behave this way: an anaphor doesn't always pick up the exact "sense" of its antecedent. For instance, take 'Rob's Ford has won Car and Driver's Ten Best award five years in a row, but this morning it won't start'. The antecedent can be about the type while the anaphor is used to refer to the token (otherwise, every literal use of the sentence would be false). Yet we shouldn't conclude that 'Rob's Ford' isn't polysemous. Here are some other nice examples, from Nunberg 1979, 1995:

(12) Yeats did not enjoy hearing himself read aloud.

(13) The window was broken so many times that it had to be boarded up.

(14) Tom sat down to read the New York Times, which minutes before had fired its president.

(15) After drinking all three bottles, Scott smashed them against his head. 
In short, the peculiar anaphoric behavior of 'its' in (11) does not provide evidence against 'Muddy York' and 'Toronto' being polysemous in the suggested object-at-a-time versus object-over-time way.

Third objection, due to Jill Rusin (personal correspondence). It's an obvious feature of our view that Ray could speak truly in saying (16):

(16) Toronto did not evolve into Toronto.

The truth of this statement is precisely part of what gets the puzzle going. A less obvious and potentially problematic feature of the view is that Rob could speak truly in saying (17):

(17) Toronto did evolve into Toronto.

That's because, on our account, 'Toronto' is not just polysemous, it is also context sensitive in another sense. Like 'he', 'Toronto' can be used on its at-a-time sense to refer to the city at different times. Thus the first 'Toronto' in an utterance of (17) might be used to refer to the city on the day of its founding in 1793, and the second might be used to refer to Toronto on VE Day. So used, the speaker (say, Rob) states something true with this sentence. (Compare 'That evolved into that': it is overtly context sensitive, and it can be used to say something true, by demonstrating first the little town and then the metropolis.) But, continues the objection, if Ray can speak truly with (16) and Rob can speak truly with (17), it seems that one could use (18) truly as well:

(18) Ray said that Toronto did not evolve into Toronto, and Rob said that Toronto did evolve into Toronto, and what they both said is true.

But, and here is the nub of the objection, (18) just can't be used truly. This counts against our view that 'Toronto' can shift its reference: it doesn't behave like authentic reference-shifters such as 'he'. The argument is clever. Our reply, however, is that once the context is right, one can use (18) truly. For instance, Ray could speak normally, while Rob could say the first 'Toronto' in a small quiet voice and the second loudly and with enthusiasm. Ray would then have spoken truly, about the object-overtime, and Rob would have spoken truly about the object at a distinct timefor example, speaking truly about the evolution of Toronto the small reserved town into Toronto the vibrant multiethnic megacity. Deploying (18) would, it must be granted, typically be an odd way of reporting this event, but that doesn't mean it cannot be used to speak the truth. Besides, imagine both the speaker and addressee have had the benefit of reading the present essay, and the speaker wants to remind the addressee about 
the view. Then, the speaker could say (18), speak truly, and speak felicitously! ${ }^{6}$

The final objection is that our view is metaphysically untenable. In particular, goes the objection, our "solution" introduces time slices, or temporal parts, or something like that. This is problematic on a host of fronts. For instance, it's unclear how such slices/parts relate to ordinary objects, and it's unclear how an early time slice (or part) can evolve into a later one, since the former has ceased to exist by the time the latter comes onto the stage. Our reply is that our view has no such implication, and this in two senses. First, the appeal to polysemy is about natural language semantics; it simply is not about metaphysics in and of itself. So we certainly do not intend any controversial metaphysical commitments. Second, so far as we can tell, our semantic claims do not entail any one view about the metaphysics of objects at a time versus objects over time. That's because all our view requires is:

a. that people can refer to an object-at-a-time;

b. that people can refer to an object-over-time;

c. that there is some difference between doing these two things; and

d. that objects at a time "evolve into" (whereas objects over time "evolve").

Any metaphysics consistent with (a)-(d) is fine by us, and there are surely lots of metaphysical views that can endorse these.

We would add that any plausible metaphysics has got to be consistent at least with (a)-(c), because they are patently true. Starting with (a) and (b), one can, for example, refer now to Elton John at the moment that Goodbye Yellow Brick Road was released. Indeed, we just did. One can also refer to Elton during his entire life. We just did that too. As for (c), that there's some difference is clear from the fact that Elton on the release date, way back in 1973, has different kinds of properties from Elton over time. For instance, Elton at the moment the album was released had a height and weight, whereas Elton over time only has an average height and weight; Elton at the moment the album appeared in stores was surely wearing a certain pair of glasses, whereas Elton over time has worn many, many different pairs of glasses; and so on. And, of course, whereas the man over time has two names, 'Elton John' and 'Reg Dwight', the man at the time of his birth had only one name, namely 'Reg Dwight'.

The sticking point is (d). In particular, it's not obvious that what one refers to when speaking of (say) Toronto at a time is a thing at all, let alone a thing that "evolves into." Now, granting this, we don't immediately have to 
buy any specific metaphysical story about what an object-at-a-time is, such that it can evolve into: whatever the right story is, we can endorse it. Still, that we can refer to such a thing does seem to be a (metaphysical?) commitment of our view. As hinted at the very outset, this is a consequence we are a bit uneasy with. Still, it's better than the obvious bizarre bullets that must be bitten, if (P1) or (P2) is abandoned. That, then, is the minor bullet that we bite.

\section{Using Polysemy to Solve the Puzzle}

Our proposal is that the names of places, people, and things are polysemous. In particular, they permit literal reference either to the object-overtime, or to the object-at-a-time. We gave three arguments for this idea and responded to four arguments against it. What remains is to put the proposal to work, to solve the puzzle with which we began. The game plan is to explain, for each premise, how it turns out to be true without yielding the contradictory conclusion. Along the way, we also want to highlight an insight that lies behind each of the "easy outs."

Start with premises 3 and 4. (P3) is plain true: '_ evolves into_' just does apply to the object however conceived. What was right about rejecting it, however, was the insight that there is reference-shifting going on. But, on our view, the reference shifting isn't of the sort Frege envisaged, that is, the kind triggered by an opaque context. Instead, it's merely a matter of one of the two use-potentials of a polysemous name (viz., the at-atime one) being salient because the linguistic context (viz., '_ evolves into') pragmatically calls for that kind of referent. As for (P4), it is true when 'Toronto' is used to refer univocally to the object over time. It is also true when 'Toronto' is used univocally to refer to the object at the same time. The insight we can glean from the Saul-style strategy, rejected earlier, is that pragmatics can play an unexpected role, namely to explain why one can use 'Toronto evolved into Toronto' truly, to talk of an object at different times. (E.g., 'Toronto evolved into TORONTO'.)

Turning to premises 1 and 2, we come to the heart of the solution to the puzzle. (P1) is true when 'Muddy York' and 'Toronto' are both used to refer to the object-over-time. Nevertheless, and this is an insight of the first "easy out," (P1) is false on another reading: the one where the two names are used to talk about distinct objects-at-a-time. As for (P2), it is true when 'Muddy York' and 'Toronto' are each used to refer to the city at different times. The insight of the second "easy out" is that (P2) is false on another reading, namely where both names are employed to refer to the city over 
time. Crucially, (P2) is false on the reading in which (P1) is true, and (P1) is false on the reading on which (P2) is true. There is thus no way to make all the premises true. That's why the argument fails.

But why do we not notice the slide? For instance, why is the argument using (P1)-(P4) so much more puzzling than the argument that uses (P1*)$\left(\mathrm{P}^{\star}\right)$ ? (No one would be even initially fooled by the latter.) The answer, we think, is that (P1) and (P2) each have exactly one salient reading: it's wholly natural to read (P1) as only being about the object-at-a-time, and wholly natural to read (P2) as being only about the object over time. And so read, they are both true. Thus the polysemy does not jump out at us. It takes hard work to see that (P1) can also be used to talk about the early waterlogged city versus the modern metropolis-and that the statement so made would be false, because those are not numerically identical. And it takes hard work to realize that (P2) can be used to talk about the single city throughout its history-and that the statement so made would be false, because that object didn't evolve into Toronto. (It is Toronto.) Once the work has been done, however, we think the original argument loses its force.

The solution, in sum, is that all the premises seem true because they all are true on their most salient reading. Thus the right approach is not to reject any premise on its most salient reading: that only leads to bullet-biting or predictions that aren't empirically borne out. The problem, rather, is one of equivocation: 'Toronto' is being used one way in (P1), and a different way in (P2).

\section{Acknowledgments}

We would like to thank the two anonymous referees for their excellent comments and suggestions. We are grateful to Fred Adams, Michael Allers, Kent Bach, Harriet Barber, Lenny Clapp, Irwin Goldstein, Tim Kenyon, Martin Montminy, Adam Morton, Michael Rea, Jay Newhard, Ted Sider, and Catherine Wearing for comments on an earlier draft. Thanks also to Catherine Elgin for a stimulating conversation early on that helped us think through the issues. An early draft of this essay was presented at the 2004 Ontario Philosophical Society Meeting at Wilfred Laurier University. We are also grateful to the audience members, and especially our commentator Jill Rusin, for their assistance. A later version was presented at the 2005 Northwest Inland Philosophy Conference on Time and Identity. We would like to thank Mark Moyer for his comments at that meeting. We are grateful to the Social Sciences and Humanities Research Council of Canada for our research grant that enabled us to write this essay. 


\section{Notes}

1. On the other hand, we don't mean to suggest that our proposal is neutral to any metaphysical theory about change. If endurantism, for instance, really does entail that one cannot talk about the young George Washington who chopped down a cherry tree but only about Washington over time, then so much the worse for it. If, in contrast, endurantism can allow for talk about objects-at-a-time and objectsover-time, then it is consistent with our approach. One who thinks that our view begs certain metaphysical questions must be assuming that linguistic referential acts are successful only if the objects of those acts exist (in the metaphysically loaded sense at work here). We are not committed to that assumption. We are, though, committed to a more modest but true claim, namely, that we have a linguistic ability to refer to all different kinds of things.

2. One solution that we will not consider is the metalinguistic solution: the name, 'Toronto', is used nonliterally in (P2) although (P2) is used literally to assert a historical truth-(P2) means something like "Muddy York became known as "Toronto". We won't consider it because it is not an "obvious" out to the puzzle. For one thing, there is no semantic hint of anything metalinguistic about (P2), and thus, there is no plausible reason for advancing that reading. (For a defense of a metalinguistic view of the semantics of proper names, see Bach 1987 and Katz 1990. Kent Bach later revised his view in Bach 2002.) For another, (P2) is not necessarily extensionally equivalent to the corresponding metalinguistic reading for familiar Kripkean reasons, assuming that names for cities are rigid designators. Thus, they are not semantically equivalent in meaning.

3. Some metaphysicians will beg to differ. For example, endurantists will take (P2) as being semantically trivially true (if (P1) is true) or trivially false (if (P1) is false). Furthermore, they will take sentences of the form, ' $x$ became $F$ ', as being the primary form of expression of change-over-time, where ' $F$ ' is a descriptive predicate, and contend that such sentences are true just in case the object in question lacks $F$ at some time and is $F$ at some later time-it is numerically one and the same object (over time) that changes its properties. The idea is to treat (P2) as being semantically equivalent in meaning to 'Muddy York became Toronto', and then specify the truth conditions of the latter in a manner that doesn't countenance distinct objects-at-a-time as relata. Without getting embroiled in a metaphysical debate, we only wish to point out that, on the present proposal of understanding change, (P2) entails that Muddy York evolved into itself given the truth of (P1). If 'evolved into' is reflexive, then it follows that Muddy York evolved into itself only if there is a single object (over time) that at one time wasn't self-identical but which (that very same object over time) is self-identical at some later time. Given the choice between accepting this rather bizarre result and accepting the claim that 'evolved into' is irreflexive, we will gladly opt for the second. We don't deny, of course, that Muddy 
York qua object-over-time has been evolving. We do, however, think that it is very important to distinguish the process of evolving from the relation of $x$ evolving into $y$. (See note 6.)

4. Putting the point in this crude way is helpful because it shows that we are not claiming that 'Toronto' refers to objects-at-a-time primarily and to an objectover-time only derivatively, or vice versa. Quite the contrary: we think that both use-potentials are semantically on a par, which is consistent with the view, developed below, that 'Toronto' has a single semantic meaning that underdetermines what a speaker means to be referring to with 'Toronto' in different contexts of use.

5. We are by no means alone in blaming the nominal, rather than the predicate, for the failure of substitution in 'The temperature is rising'. We aren't exactly sure who noted the point first, but it goes back at least as far as Michael Bennett and Barbara Partee's work in the mid-1970s.

6. It's interesting to compare in this regard 'Toronto evolved into itself' versus 'Toronto evolved into Toronto'. Putting aside "proxy readings" — such as Ringo Starr bumping into a wax figure of the Beatles' drummer, described as 'Ringo Starr knocked over himself' - we find the former much worse than that latter; and this fits with our view that 'Toronto evolved into Toronto' can be used to talk about one thing evolving into another. (See Jackendoff 1992 for discussion.)

\section{References}

Apresjan, J. D. 1974. Regular Polysemy. Linguistics 142:5-32.

Bach, K. 1987. Thought and Reference. Oxford: Oxford University Press.

Bach, K. 2002. Georgione Was So-Called Because of His Name. In Philosophical Perspectives: Language and Mind, vol. 16, ed. J. E. Tomberlin. Oxford: Blackwell.

Fodor, J., and E. Lepore. 1998. The Emptiness of the Lexicon. Linguistic Inquiry 29:269-288.

Jackendoff, R. 1992. Mme Tussaud meets the Binding Theory. Natural Language and Linguistic Theory 10:1-31.

Katz, J. J. 1990. Has the Description Theory of Names Been Refuted? In Meaning and Method: Essays in Honour of Hilary Putnam, ed. G. Boolos. Cambridge: Cambridge University Press.

Moravcsik, J. 1998. Meaning, Creativity, and the Partial Inscrutability of the Human Mind. Stanford, CA: CSLI Publications.

Nunberg, G. 1979. The Non-Uniqueness of Semantic Solutions: Polysemy. Linguistics and Philosophy 3:143-184. 
Nunberg, G. 1995. Transfers of Meaning. Journal of Semantics 12:109-132.

Pustejovsky, J. 1998. The Generative Lexicon. Cambridge, MA: MIT Press.

Saul, J. 1997. Substitution and Simple Sentences. Analysis 57:102-108.

Strawson, P. F. 1950. On Referring. Mind 59:320-344. 